\title{
Effects of $0.5 \%$ apraclonidine on optic nerve head and peripapillary retinal blood flow
}

\author{
Tae Woo Kim, Dong Myung Kim
}

\begin{abstract}
Aims-To examine the effects of $0.5 \%$ apraclonidine on optic nerve head (ONH) and peripapillary retinal blood flow by scanning laser Doppler flowmetry (SLDF).

Methods-ONH and peripapillary retinal blood flow of 17 healthy subjects were measured by SLDF before and 1 hour and 3 hours after unilateral administration of $0.5 \%$ apraclonidine. The fellow eyes were treated with balanced salt solution and the examiners were masked as to which eye was treated with apraclonidine. On each occasion, three scans were obtained and haemodynamic variables (volume, flow, and velocity) were analysed at eight locations, four in the neural rim and four in the peripapillary retina, avoiding ophthalmoscopically visible vessels. The statistical significance of changes from the baseline value of variables and the differences in the measured quantities between apraclonidine treated eyes and fellow eyes at each time point were evaluated using Wilcoxon signed rank test.
\end{abstract}

Results-The intraocular pressure was reduced significantly in apraclonidine treated eyes by $15.0 \%(p=0.001)$ at 1 hour and $30.0 \%(p=0.000)$ at 3 hours after administration. In the volume, flow, or velocity of $\mathrm{ONH}$ and peripapillary retinal blood flow, there were no significant changes from the baseline values at 1 hour and 3 hours after apraclonidine administration in either apraclonidine treated eyes $(p>0.4)$ or fellow eyes $(p>0.2)$. Also, no significant differences were found in the measured quantities between apraclonidine treated eyes and fellow eyes at each time point $(p>0.1)$.

Conclusion-A single dose of topical apraclonidine $0.5 \%$ in healthy subjects does not have adverse effects on the $\mathrm{ONH}$ and peripapillary retinal blood flow.

Ophthalmology, Seoul

National University

Hospital, Seoul, Korea

T W Kim

D M Kim

Correspondence to: Dong Myung Kim, MD, Department of

Ophthalmology, Seoul

National University Hospital,

28 Yeongun-Dong,

Chongro-Ku, Seoul 110-744,

Korea.

Accepted for publication 13 August 1997 striction of the precapillary sphincters in the vessels supplying the ciliary body. ${ }^{7}$ Several side effects have been noted with apraclonidine administration, including lid retraction, mydriasis, conjunctival blanching, and allergic reaction. Clinically apparent conjunctival blanching is associated with conjunctival hypoxia, with a reduction of conjunctival oxygen tension to $76 \%$ of baseline values at 1 hour, which lasts up to 5 hours after administration of apraclonidine. ${ }^{8}$

Studies have been made to examine whether apraclonidine administration also exerts a vasoconstrictive action on the optic nerve head $(\mathrm{ONH})$ or retina. Colour Doppler ultrasound measurements of ophthalmic and central retinal arteries suggested that apraclonidine does not have adverse vasomotor effect on retinal arterial blood flow. ${ }^{9}{ }^{10}$ Evaluation of vasoconstriction of arterioles supplying the anterior optic nerve using intraluminal corrosion casting technique showed no significant differences between the apraclonidine treated and untreated eyes. ${ }^{11}{ }^{12}$ We measured the effects of apraclonidine on capillary blood flow in $\mathrm{ONH}$ and peripapillary retina using scanning laser Doppler flowmetry (SLDF).

Subjects and methods

Seventeen healthy subjects were recruited. They included 12 men and five women with a mean age of 27.5 years (range 25 to 35 years). Subjects were excluded if they had undergone previous intraocular or laser surgery, worn contact lenses within 2 days before the study, had evidence of a current eye infection, or had taken any medications within 2 weeks of the study. After informed consent was obtained,

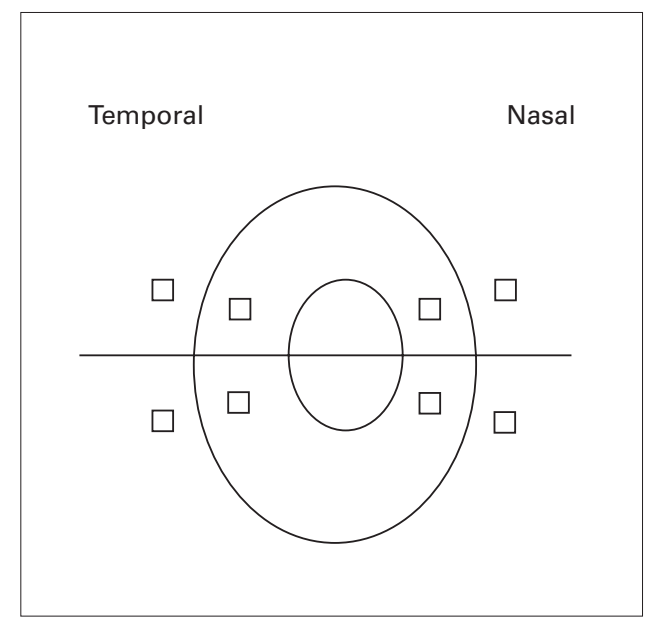

Figure 1 Schematic diagram showing eight locations where haemodynamic variables were measured. The four retinal points were located approximately $100 \mu \mathrm{m}$ from the edge of the optic disc. 
Table 1 Cardiovascular responses to $0.5 \%$ apraclonidine instilled after baseline measurement (mean (SEM), $n=17$ )

\begin{tabular}{lcrr}
\hline & Baseline & 1 hour & 3 hours \\
\hline Heart rate (beats/min) & $73(1)$ & $73(1)$ & $74(2)$ \\
Blood pressure (mm Hg) & & & $116(4)$ \\
systolic & $117(4)$ & $77(2)$ & $79(2)$ \\
diastolic & $78(2)$ & $90(2)$ & $91(2)$ \\
mean arterial & $91(2)$ & & \\
\hline
\end{tabular}

Table 2 Intraocular pressure and calculated perfusion pressure responses to $0.5 \%$ apraclonidine instilled after baseline measurement (mean (SEM), $n=17$ )

\begin{tabular}{|c|c|c|c|}
\hline & Baseline & 1 hour & 3 hours \\
\hline \multicolumn{4}{|l|}{ Intraocular pressure $(\mathrm{mm} \mathrm{Hg})$} \\
\hline apraclonidine treated eyes & $15.4(0.7)$ & $\begin{array}{l}13.0(0.6) \\
(\mathrm{p}=0.001)\end{array}$ & $\begin{array}{l}10.8(0.4) \\
(\mathrm{p}=0.000)\end{array}$ \\
\hline fellow eyes & $15.2(0.6)$ & $\begin{array}{l}14.9(0.6) \\
\text { (NS) }\end{array}$ & $\begin{array}{l}14.9(0.6) \\
\text { (NS) }\end{array}$ \\
\hline $\begin{array}{l}\text { Calculated ocular perfusion pressure }(\mathrm{mm} \mathrm{Hg}) \\
\text { apraclonidine treated eyes }\end{array}$ & $45(2)$ & $\begin{array}{l}47(2) \\
(p=0.001)\end{array}$ & $\begin{array}{l}50(2) \\
(p=0.000)\end{array}$ \\
\hline fellow eyes & $45(2)$ & $\begin{array}{l}45(2) \\
\text { (NS) }\end{array}$ & $\begin{array}{l}46(2) \\
\text { (NS) }\end{array}$ \\
\hline
\end{tabular}

NS = not significant.

heart rate (by radial artery pulsation), blood pressure (by sphygmomanometry), and IOP (by non-contact applanation tonometry) were measured three times. $\mathrm{ONH}$ and peripapillary retinal blood flow of each eye was measured by SLDF. Subjects then received two drops of $0.5 \%$ apraclonidine in a randomly selected eye and two drops of balanced salt solution in the fellow eye as a placebo. The drug and placebo drops were provided with coded labels so that neither the investigators nor the subjects had any knowledge of which eye was receiving the drug. Measuring IOP, heart rate, blood pressure, and blood flow in the $\mathrm{ONH}$ and peripapillary retina were repeated 1 hour and 3 hours after instillation. On each occasion of SLDF, three scans centred on the $\mathrm{ONH}$ using a $10 \times$ 2.5 degrees scan angle were obtained.

The principle, validity, and reliability of SLDF have been described previously. ${ }^{13}$ The scanning laser Doppler flowmeter (Heidelberg retina flowmeter, Heidelberg Engineering $\mathrm{GmbH}$, Heidelberg, Germany) used in this study combines a laser Doppler flowmeter with a scanning laser system by which the retinal perfusion is simultaneously quantified in a area of $2.7 \times 0.7 \mathrm{~mm}$ composed of 64 horizontal lines of 256 points and provides a two dimensional map showing the microvascular perfusion of the retina and $\mathrm{ONH} .{ }^{14}$ Each line is scanned sequentially a total of 128 times with a diode laser for approximately 2 seconds. Blood

Table 3 Volume, flow, and velocity of the optic nerve head and peripapillary retinal blood flow measured by scanning laser Doppler flowmetry (mean (SEM), $n=17$ )

\begin{tabular}{|c|c|c|c|c|c|c|}
\hline & \multicolumn{2}{|l|}{ Volume } & \multicolumn{2}{|l|}{ Flow } & \multicolumn{2}{|l|}{ Velocity } \\
\hline & $A E$ & $F E \dagger$ & $A E$ & FE† & $A E$ & FE† \\
\hline \multicolumn{7}{|l|}{ Neural rim } \\
\hline baseline & $19.45(0.94)$ & $18.48(0.85)$ & $454.26(20.69)$ & $443.15(30.33)$ & $1.55(0.07)$ & $1.55(0.11)$ \\
\hline 1 hour ${ }^{\star}$ & $19.27(1.02)$ & $20.84(0.93)$ & $459.81(32.40)$ & $481.95(31.18)$ & $1.59(0.10)$ & $1.81(0.12)$ \\
\hline 3 hours* & $18.99(0.78)$ & $19.31(0.67)$ & $462.28(32.01)$ & $468.42(22.81)$ & $1.61(0.10)$ & $1.73(0.08)$ \\
\hline \multicolumn{7}{|c|}{ Peripapillary retina } \\
\hline baseline & $19.59(0.72)$ & $19.08(0.88)$ & $354.28(21.01)$ & 340.78 (19.38) & $1.22(0.07)$ & $1.18(0.06)$ \\
\hline 1 hour $\star$ & $19.75(1.71)$ & $19.15(0.95)$ & $359.88(18.29)$ & $346.68(22.14)$ & $1.23(0.06)$ & $1.19(0.07)$ \\
\hline 3 hours* & $19.48(0.07)$ & $19.79(0.97)$ & $355.23(28.99)$ & $377.80(18.00)$ & $1.27(0.09)$ & $1.25(0.09)$ \\
\hline
\end{tabular}

*No significant changes from the baseline values in either $\operatorname{AE}(\mathrm{p}>0.4)$ or $\mathrm{FE}(\mathrm{p}>0.2)$.

+ No significant differences between $\mathrm{AE}$ and $\mathrm{FE}$ at each time point $(\mathrm{p}>0.1)$.

$\mathrm{AE}=$ apraclonidine treated eyes $; \mathrm{FE}=$ fellow eyes. volume, flow, and velocity can be quantified in any location of the perfusion map by placing a square of variable size $(1 \times 1,4 \times 4$, or $10 \times 10$ pixels, or larger) in the area of interest. The values of each pixel within this square are averaged and the final results are given for blood volume, flow, and velocity.

All images were reviewed by the same observer. Haemodynamic variables (volume, flow, and velocity) were analysed at eight locations, two each in the temporal and nasal neural rim and two each in the temporal and nasal peripapillary retina, avoiding ophthalmoscopically visible vessels (Fig 1). The analysis window was $10 \times 10$ pixels $(100 \times 100 \mu \mathrm{m})$ and each window was located at the same area as closely as possible in each subject. In eyes with peripapillary atrophy, windows were located outside of that to measure peripapillary retinal be measured was unaware of the results of the measurements because the part of the monitor where the values appeared was masked.

Three scans of each occasion were all analysed and the averages of the measurements on three scans were used for statistical analysis. Wilcoxon signed rank test was applied to evaluate the statistical significance of changes from the baseline value of blood flow variables and the differences in the measured quantities between apraclonidine treated eyes and fellow eyes.

\section{Results}

The heart rate and blood pressure at each time point are summarised in Table 1. Compared with the baseline values, there were no statistically significant differences in the heart rate and blood pressure at 1 hour or 3 hours after instillation of apraclonidine $(\mathrm{p}>0.2)$.

The IOP was reduced in apraclonidine treated eyes by $15.0 \%(\mathrm{p}=0.001)$ at 1 hour and $30.0 \%(p=0.000)$ at 3 hours after administration when compared with baseline values (Table 2). Calculated ocular perfusion pressure (COPP, 2/3 mean arterial pressure - IOP) was increased by $4.4 \%(\mathrm{p}=0.002)$ at 1 hour and $11.0 \%(p=0.000)$ at 3 hours after administration. In the fellow eyes, the IOP and COPP did not vary significantly compared with baseline values.

In the volume, flow, or velocity of $\mathrm{ONH}$ and peripapillary retinal blood flow, there were no significant changes from the baseline values at blood flow. The observer who chose the area to 
1 hour and 3 hours after apraclonidine administration in either apraclonidine treated eyes $(p$ $>0.4$ ) or fellow eyes $(p>0.2)$. Also, no significant differences were found in the measured quantities between apraclonidine treated eyes and fellow eyes at each time point $(\mathrm{p}>0.1)$ (Table 3).

\section{Discussion}

Apraclonidine demonstrated ocular hypotensive, but not systemic hypotensive, actions which is in accord with previous studies. ${ }^{15}$

Apraclonidine penetrates the eye via the conjunctival/scleral pathway because of its relatively low lipophilicity. ${ }^{16}$ The drug serves as an agonist at $\alpha_{2}$ adrenoceptors in the ciliary epithelium ${ }^{17}$ and at vasoconstrictive $\alpha_{2}$ adrenoceptors in all regions of the eye to which it has access. In the present study, topical administration of $0.5 \%$ apraclonidine did not significantly change the $\mathrm{ONH}$ and peripapillary retinal blood flow, while lowering the IOP. These results suggest three possibilities.

Firstly, apraclonidine may not penetrate posterior to the $\mathrm{ONH}$ and peripapillary retina to influence the haemodynamics of that area. Secondly, vasoconstrictive $\alpha_{1}$ and $\alpha_{2}$ adrenoceptors may be absent in $\mathrm{ONH}$ and peripapillary retinal vessels. Thirdly, the change in the blood flow is within the variability of measurement by SLDF.

The independence of the ocular haemodynamics from the short term or chronic application of topical apraclonidine has been reported in rabbits, ${ }^{11} 12$ cats, ${ }^{18}$ and human subjects ${ }^{9}$ with the use of corrosion casting technique, laser Doppler flowmeter imaging, or colour Doppler imaging (CDI). However, these measurements were accomplished at arterioles supplying the anterior optic nerve or ophthalmic and central retinal arteries. Using the Heidelberg retinal flowmeter, which provides physiological picture of the $\mathrm{ONH}$ and retinal perfusion with visualisation of capillaries, we measured the haemodynamic variables in the capillary bed. This assessment reflects the actual tissue perfusion more accurately than corrosion casting technique or CDI.

While the $\mathrm{ONH}$ and peripapillary retinal blood flow remain unchanged, the COPP was increased significantly as the IOP lowered after apraclonidine administration. This apparently incompatible result may be explained by the autoregulatory mechanisms of the $\mathrm{ONH}$ and peripapillary microcirculations that control the blood flow to be unchanged against the elevated ocular perfusion pressure. Otherwise, the possibility that vasoconstrictive activity of apraclonidine prevents blood flow from increasing in response to the increased perfusion pressure cannot be ruled out.

In conclusion, our results confirm that a single dose of topical apraclonidine $0.5 \%$ in healthy subjects does not have adverse effects on the $\mathrm{ONH}$ and peripapillary retinal blood flow. None the less, further studies are needed to confirm the safety of this medication in glaucomatous eyes with regard to optic nerve perfusion.

1 Jampel HD, Robin AL, Quigley HA, Pollack IP. Apraclonidose-response study. Arch Ophthalmol 1988;106:1069-73.

2 Abrams DA, Robin AL, Crandall AS, Caldwell DR, Schnitzer DB, Pollack IP, et al. A limited comparison of apraclonidine's dose response in subjects with normal to increased intraocular pressure. Am f Ophthalmol 1989;108: increased.

3 Abramn DA, Robin Al, Pollack IP, deFaller JM, DeSantis L. The safety and efficacy of topical $1 \%$ ALO 2145 p-aminoclonidine hydrochloride) in normal volunteers. Arch Ophthalmol 1987;105:1205-7.

4 Nagasubramanian S, Hitchings RA, Demailly P, Chuniaud M, Pannarale MR, Pecori-Giraldi J, et al. Comparison of apraclonidine and timolol in chronic open-angle glaucoma. Ophthalmology 1993;100:1318-23.

5 Morrison JC, Robin AL. Adjunctive glaucoma therapy: a comparison of apraclonidine to dipivefrin when added to timolol maleate. Ophthalmology 1989;96:3-7.

6 Toris CB, Tafoya ME, Camras CB, Yablonski ME. Effects of apraclonidine on aqueous humor dynamics in human eyes. Ophthalmology 1995;102:456-61.

7 Fahrenbach WH, Bacon DR, Van Buskrick EM. Vasoactive drug effects in the uveal vasculature of the rabbit: a corrosion casting study. Invest Ophthalmol Vis Sci 1989; 30(suppl): 100 .

8 Serdahl CL, Galustian J, Lewis RA. The effects of apraclonidine on conjunctival oxygen tension. Arch Ophthalmol 989;107:1777-9.

9 Harris A, Caldemeyer KS, Mansberger SL, Martin BJ. $\alpha$-Adrenergic agonists' effects on ocular hemodynamics. $\mathscr{f}$ Glaucoma 1995;4(suppl.1):S19-S23.

10 Çeliker ÜÖ, Çelebi S, Çeliker H, Çelebi H. Effect of topical apraclonidine on flow properties of central retinal and ophthalmic arteries. Acta Ophthalmol 1996;74:151-4.

11 Cioffi GA, Orgül S, Bacon DR, Van Buskirk EM. Acute vasomotor effects in the anterior optic nerve of topical apraclonidine hydrochloride. F Glaucoma 1995;4(Suppl 1):S15-S18.

12 Orgül S, Bacon DR, Van Buskirk EM, Cioffi GA. Optic nerve vasomotor effects of topical apraclonidine hydrochloride. Br f Ophthalmol 1996;80:82-4.

13 Michelson G, Schmauss B, Langhans MJ, Harazny J, Groh MJM. Principle, validity and reliability of scanning laser MJM. Principle, validity and reliability of scan
Doppler flowmetry. F Glaucoma $1996 ; 5: 99-105$.

14 Heidelberg Engineering GmbH. Heidelberg Retina FlowHeidelberg Engineering GmbH. Heidelberg Retina Flow-
meter Operation Software Release 1.01, July 1995 Rev meter $1.02-1$.

15 Robin AL. Short-term effects of unilateral $1 \%$ apraclonidine therapy. Arch Ophthalmol 1988;106:912-5.

16 Chien D-S, Homsy JJ, Gluchowski C, Tang-Liu DDS. Corneal and conjunctival/sclearl penetration of p-aminoclonidine, AGN 190342, and clonidine in rabbit eye. Curr Eye Res 1990;9:1051-9.

17 Elena PP, Kosina-Boix M, Denis P, Moulin G, Lapalus P. Alpha2-adrenergic receptors in rat and rabbit eye. A ritium-sensitive film autoradiography. Ophthalmic Res 1989;21:309-14.

18 Barnes GE, Riva CE, Chandler ML, DeSantis L. Retinal and optic nerve head blood flow response to apraclonidine in anesthetized cats. Invest Ophthalmol Vis Sci 1993;34: 1394. 